
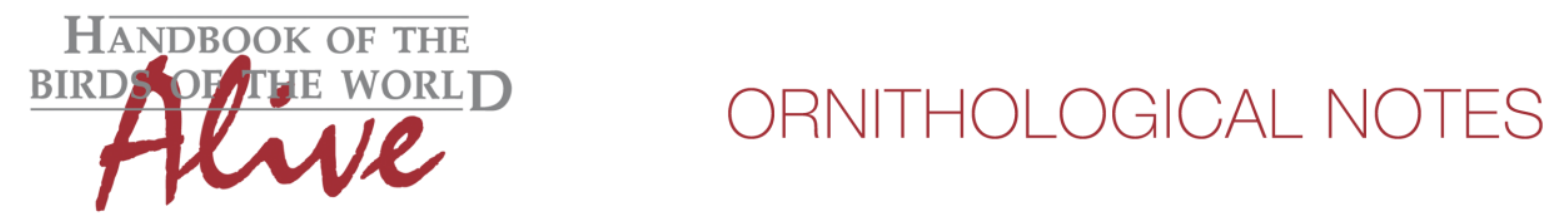

\title{
Notes on the vocalizations of Tibetan Blackbird (Turdus maximus)
}

Peter Boesman

In the following we briefly analyze and compare voice of the different races of Tibetan Blackbird (Turdus maximus). We also try to quantify the extent of any vocal differences using the criteria proposed by Tobias et al. (2010), as a support for taxonomic review.

We have made use of sound recordings available on-line from Xeno Canto (XC) and Macaulay Library (ML).

The Ripley guide (Rasmussen \& Anderton 2012) describes voice as being very distinct, being poor and monotonous with many repetitions, lacking warbles and trills as in Common Blackbird Turdus merula.

Only very few recordings of presumed song are available:

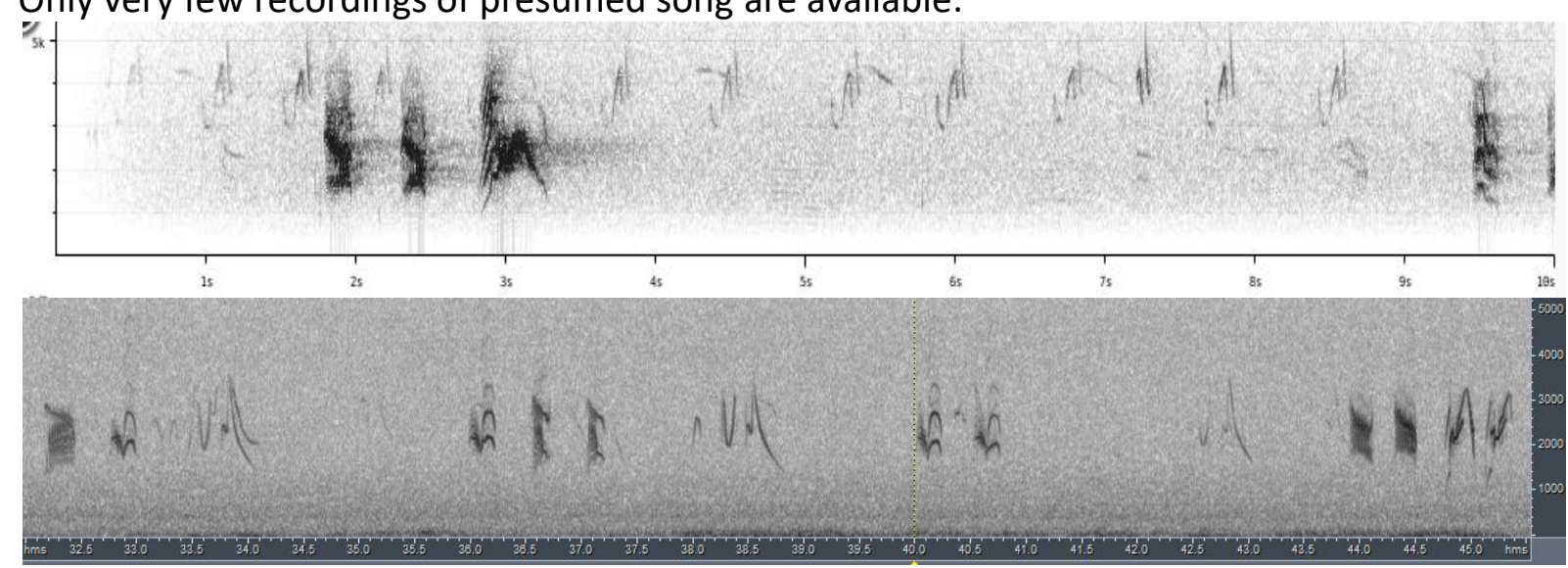

(with an additional sonogram in The Ripley Guide)

XC105305 is probably misidentified (or contradicts statements in Ripley guide, being much more whistled):

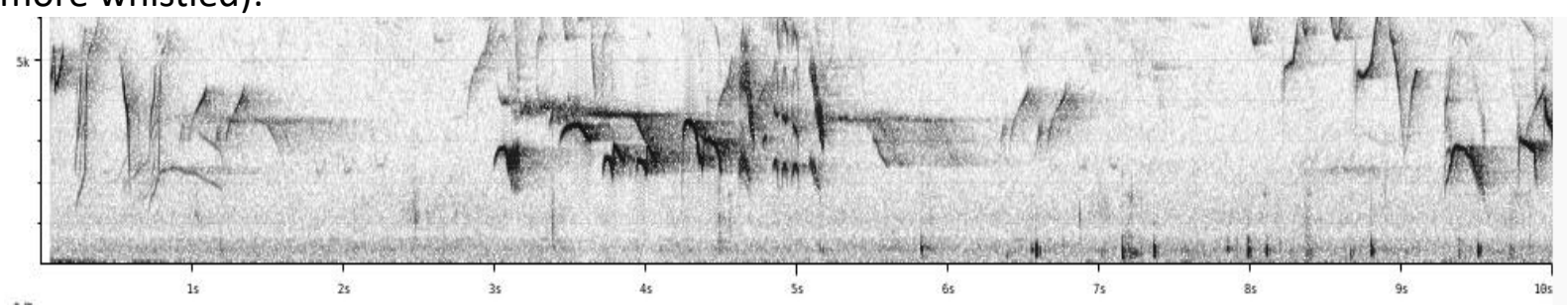

To be compared with song of Common Blackbird, which typically is a short phrase of different thrush-like throaty whistles, usually ending with higher-pitched notes. 

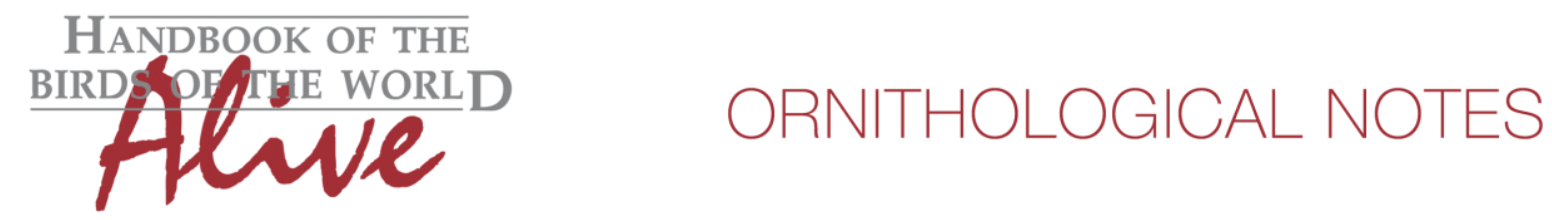

Some examples:

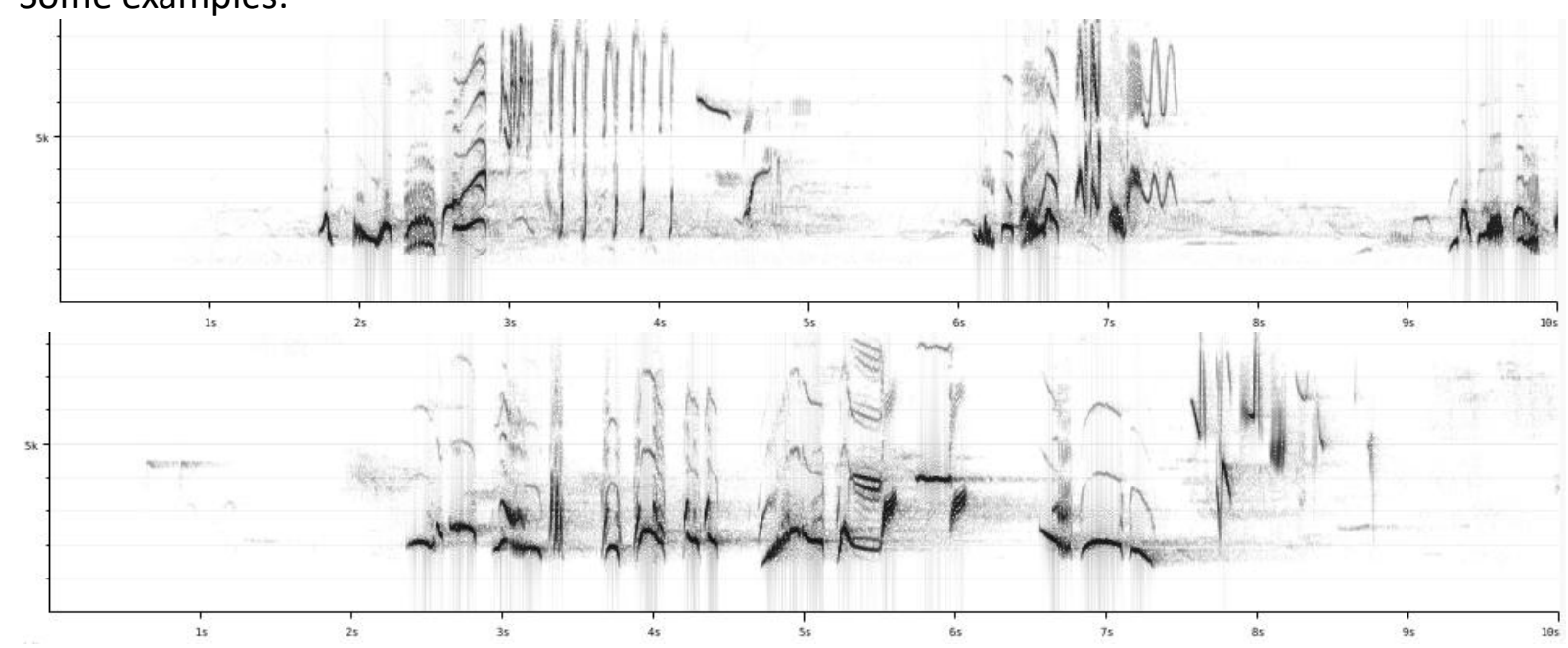

The first two examples for T. maximus clearly confirm the description in The Ripley guide. In this case, a vocal score for maximus vs. merula could be given based on its shorter song phrase length (score 2-3), lower \# of notes per phrase (score 3), lower number of different notes per phrase (score 3 ) lack of whistles and trills (score 1-2), etc.

When applying Tobias criteria this would lead to a total vocal score of about 5-6.

More recordings of song would be welcome to further support this.

This note was finalized on 20th April 2016, using sound recordings available on-line at that moment. We would like to thank in particular the sound recordists who placed their recordings for this species on XC and ML: Geoff Carey, David Farrow, Vir Joshi, Frank Lambert and Mike Nelson.

\section{References}

Rasmussen, P.C. \& Anderton, J.C. (2012) Birds of South Asia. The Ripley Guide. Second Edition. Lynx Edicions. Barcelona.

Tobias, J.A., Seddon, N., Spottiswoode, C.N., Pilgrim, J.D., Fishpool, L.D.C. \& Collar, N.J. (2010). Quantitative criteria for species delimitation. Ibis 152(4): 724-746.

\section{Recommended citation}

Boesman, P. (2016). Notes on the vocalizations of Tibetan Blackbird (Turdus maximus). HBW Alive Ornithological Note 312. In: Handbook of the Birds of the World Alive. Lynx Edicions, Barcelona. (retrieved from http://www.hbw.com/node/1251829 on 18 October 2016). 